\title{
Jejuno-ileal bypass arthropathy: its clinical features and associations
}

\author{
J. P. DELAMERE, ${ }^{1}$ R. M. BADDELEY, ${ }^{2}$ AND K. W. WALTON ${ }^{1}$ \\ From the ${ }^{1}$ Department of Investigative Pathology, the Medical School, Birmingham, and the ${ }^{2}$ Department of \\ Surgery, General Hospital, Birmingham
}

SUMMARY Postoperative arthropathy has been reported in patients undergoing jejunoileal bypass for morbid obesity. The true frequency of this complication, and its independence from preexisting joint disease and from osteomalacia, have not been clearly established. Of 107 patients who had undergone jejunoileal bypass, and in whom osteomalacia had been excluded, 38 developed a distinctive arthropathy. This consisted of episodic polyarthralgia, and occasionally arthritis, affecting both large and small joints. The articular symptom complex was independent of other major postoperative complications and unrelated to metabolic disturbances consequent upon rapid weight reduction. Preoperative joint symptoms had a similar incidence in those who did and in those who did not subsequently develop the postoperative arthropathy. Reversal of the intestinal bypass was always associated with an immediate, complete, and permanent remission of arthropathic symptoms.

The surgical management of morbid obesity by the induction of an intestinal bypass was pioneered by Payne et al., ${ }^{1}$ beginning in 1956 , after the failure of medical treatment in some patients to procure and maintain satisfactory weight reduction. The bypass procedures (initially jejunocolic and later jejunoileal) cause considerable weight loss in most patients, particularly during the first postoperative year. ${ }^{2-4}$ The complications of these operations are unfortunately numerous. They can be divided into metabolic or inflammatory on the basis of their suspected aetiology. Hyperoxaluria, nephrolithiasis, and osteomalacia are examples of the first category, while hepatic degeneration, bypass enteropathy, and arthropathy are the major inflammatory or toxic complications. ${ }^{5-8}$ The arthropathic side effects initially reported in 1971 by Shagrin et al. ${ }^{9}$ after jejunocolic bypass have since been observed, with varying incidence, in various joints and at various intervals after jejunoileal bypass. ${ }^{70-13}$ Recent debate has questioned the degree to which pre-existing joint disease and a known postoperative complication, namely osteomalacia, are responsible for these articular symptoms. ${ }^{14} 15$

The growing interest in the relationship between

Accepted for publication 2 September 1982.

Correspondence to Dr J. P. Delamere, Department of Investigative Pathology, Rheumatism Research Wing, Medical School, Birmingham. bowel pathology and arthritis ${ }^{16}$ highlights the importance of ascertaining whether a definite complex of musculoskeletal symptoms and signs, independent of other metabolic complications, develops as a consequence of this known intestinal derangement and also whether it remits with reversal of the bypass. Investigations designed to answer these questions have been carried out on morbidly obese subjects who have undergone rapid weight reduction as a result of a jejunoileal bypass, an 800 kilocalorie (3.3 MJ) diet or gastric reduction (gastroplasty), and in some patients in whom the initial jejunoileal bypass has been reversed.

\section{Patients and methods}

Three groups of patients were studied.

Group I. Consisted of 112 subjects (101 F, $11 \mathrm{M})$ who had undergone jejunoileal bypass (schematic representations of which appear in Fig. 1) 1 month to 7 years (mean 48 months) previously. All satisfied the criteria of being normouricaemic on routine serum uric acid estimations (performed 6-monthly), Rose-Waaler negative (titre $<1 / 32$ ), and unaffected by osteomalacia, as determined by yearly bone biopsies.

Group II. A total of 18 patients $(17 \mathrm{~F}, 1 \mathrm{M})$ were investigated 1 to 60 months (mean 24 months) after their jejunoileal bypass had been reversed for the 


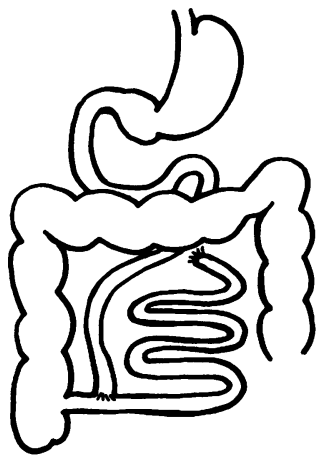

Type 1

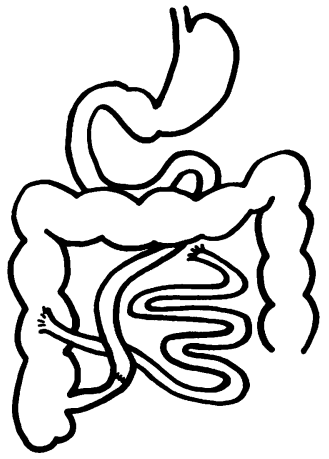

Type 2

Fig. 1 Type I jejunoileal bypass, Payne et al. ${ }^{5}$ Redundant loop of small intestine anastomosed to the terminal ileum. Type 2 jejunoileal bypass, Scott et al. ${ }^{17}$ Redundant loop of small intestine anastomosed to the colon.

Table 1 Subjects whose jejunoileal bypass had been reversed: duration of bypass and indication for its reversal

\begin{tabular}{|c|c|c|c|}
\hline Subject & $\begin{array}{l}\text { Time since } \\
\text { reversal } \\
\text { (months) }\end{array}$ & $\begin{array}{l}\text { Duration of } \\
\text { jejuno-ileal } \\
\text { bypass } \\
\text { (years) }\end{array}$ & Indication for reversal \\
\hline 1 & 6 & 6 & Hepatic degeneration \\
\hline 2 & 17 & 4 & Bypass enteropathy \\
\hline 3 & 36 & 5 & Arthropathy \\
\hline 4 & 48 & 1 & $\begin{array}{l}\text { Hepatic degeneration and } \\
\text { arthropathy }\end{array}$ \\
\hline 5 & 2 & 2 & Protein deficiency \\
\hline 6 & 6 & 7 & Heptic degeneration \\
\hline 7 & 60 & 2 & $\begin{array}{l}\text { Bypass enteropathy and } \\
\text { arthropathy }\end{array}$ \\
\hline 8 & 1 & 6 & Persistent diarrhoea \\
\hline 9 & 30 & 4 & $\begin{array}{l}\text { Persistent diarrhoea and } \\
\text { arthropathy }\end{array}$ \\
\hline 10 & 12 & 2 & Hepatic degeneration \\
\hline 11 & 48 & 1 & Bypass enteropathy \\
\hline 12 & 5 & 5 & Arthropathy and rash \\
\hline 13 & 48 & 1 & Electrolyte imbalance \\
\hline 14 & 60 & 1 & Persistent vomiting \\
\hline 15 & 18 & 3 & Hepatic degeneration \\
\hline 16 & 12 & 5 & Persistent diarrhoea \\
\hline 17 & 3 & 7 & Hepatic degeneration \\
\hline 18 & 24 & 3 & $\begin{array}{l}\text { Persistent diarrhoea and } \\
\text { arthropathy }\end{array}$ \\
\hline
\end{tabular}

indications listed in Table 1 . It will be seen that arthropathy alone or in combination with another complication was the indication for reversal in 6 patients (nos. 3, 4, 7, 9, 12, and 18 of Table 1).

Group III. Consisted of a control group of 18 patients who had undergone rapid weight reduction over 1 to 36 months (mean 11 months), induced in 10 subjects $(6 \mathrm{~F}, 4 \mathrm{M})$ by an $800 \mathrm{kcal}(3.3 \mathrm{MJ})$ diet with or without dental splintage, or by operative gastroplasty in the remaining 8 patients $(7 \mathrm{~F}, 1 \mathrm{M})$. The last procedure, while reducing the volume of the stomach, does not affect the continuity or integrity of the small intestine. ${ }^{18} 19$

The patients, who were all attending the routine morbid obesity clinic at a minimum of 6 -monthly intervals, were asked on at least 2 occasions about their musculoskeletal symptoms. Affected joints were examined and note was taken of associated complications, particularly bowel disturbances and skin rashes.

\section{Results}

\section{GRO U P I}

Five of the initial 112 jejunoileal bypass patients were excluded from the study on the basis that their histories of musculoskeletal symptoms were not consistent at repeated interviews. Thirty-eight of the remaining 107 subjects (33/98 end-to-side, 5/9 endto-end bypass) developed a characteristic arthropathy 1-78 months (mean 27 months) after operation. The age, sex, and interval since operation for the patients with and without arthropathy appear in Table 2. An episodic symmetrical polyarthralgia involving from 4 to 18 joints (mean 10 joints) was the main and in the majority of cases only feature of the arthropathy. The attacks, which were sudden in onset, involved both large and small joints, particularly those of the upper limbs, and consisted of pain exacerbated by movement and stiffness aggravated by rest. Fig. 2 illustrates the distribution of the affected joints. These episodes lasted 2-14 days and were separated by periods of 2-12 weeks, during which time the subjects were asymptomatic. Joint symptoms in most of the subjects proved little more than a minor inconvenience. However, in 5 patients

Table 2 Post-jejunoileal bypass patients with and without arthropathy: their age, sex, and interval since operation at first interview

\begin{tabular}{lcccc}
\hline Group & $\begin{array}{l}\text { No. patients } \\
(\% \text { total) }\end{array}$ & $F: M$ & $\begin{array}{l}\text { Mean age } \pm S D \\
(y r)\end{array}$ & $\begin{array}{l}\text { Mean duration } \pm S D \\
\text { jejunoileal bypass } \\
\text { (months) }\end{array}$ \\
\hline Total patients & $107(100)$ & $96: 11$ & $41 \pm 10$ & $48 \pm 24$ \\
Postoperative arthropathy & $38(35)$ & $36: 2$ & $41 \pm 9$ & $54 \pm 22$ \\
No postoperative arthropathy & $69(65)$ & $60: 9$ & $39 \pm 9$ & $42 \pm 22$ \\
\hline
\end{tabular}




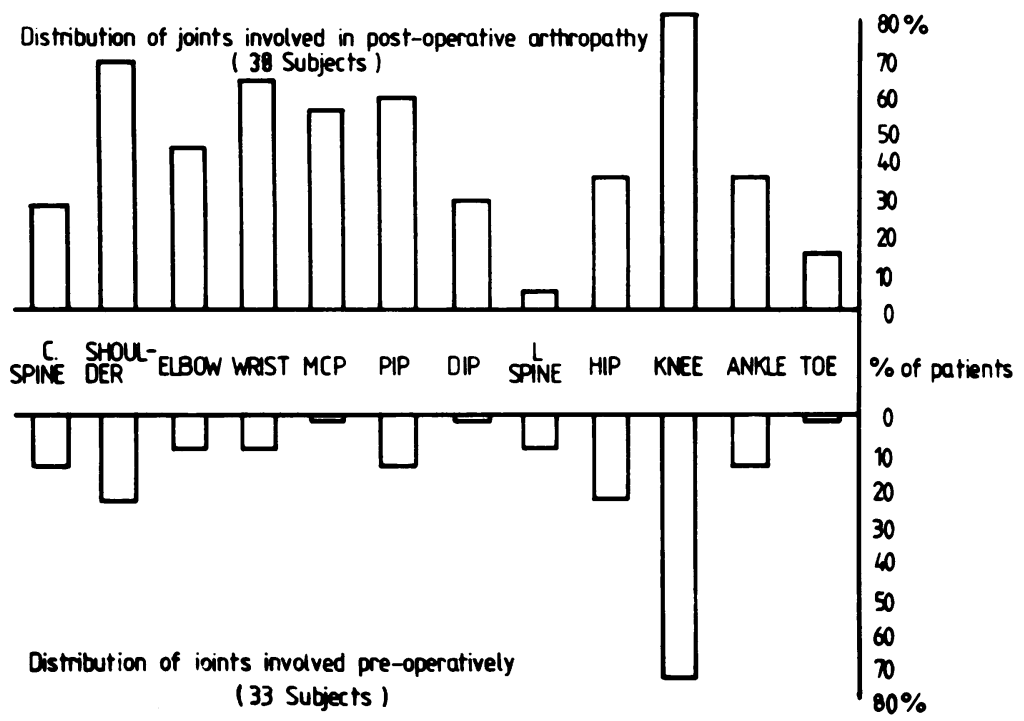

Fig. 2 Joints giving rise to preoperative symptoms compared with those involved in the postoperative arthropathy.

Table 3 Joints involved in 8 subjects with postoperative arthritis

\begin{tabular}{ll}
\hline Subject & Joints with postoperative arthritis \\
\hline 1 & Knees \\
2 & Knees, MCPs, PIPs \\
3 & MCPs, PIPs \\
4 & MCPs \\
5 & Ankles \\
6 & Wrists, knees \\
7 & Wrists \\
8 & DIPs \\
\hline
\end{tabular}

$\mathrm{MCP}=$ metacarpophalangeal joint. $\mathrm{PIP}=$ proximal interphalangeal joint. DIP = distal interphalangeal joint.

they had necessitated confinement to bed and in a further 6 functional capacity had been reduced to self-care only. The pattern of joint involvement, the severity and duration of attacks, and the interval between episodes showed a wide intergroup but little interpatient variation. In 8 of the 38 subjects evidence of an active arthritis (swelling, tenderness, and heat) was observed on at least one occasion in some of the joints, giving rise to the polyarthralgia (Table 3).

No resultant permanent joint damage was detected either clinically or radiologically. The arthropathy was self-limiting in 4 subjects, being present for 1-3 years, with no further attacks occurring during the subsequent 6-month to 3-year follow-up. Preoperative joint symptoms, resulting mainly from monoarticular involvement of large weight-bearing joints, were present at a similar incidence in those who did $(11 / 38,29 \%)$ and those who did not $(22 / 69$, $32 \%)$ subsequently develop the postoperative arthropathy. The joints giving rise to these preoperative symptoms (principally the knees) are compared in Fig. 2 with the joints involved in the postoperative arthropathy. It will be seen that, postoperatively, small and large joints were affected and particularly those of the upper limbs.

A maculopapular eruption was temporarily associated with polyarthralgia in 3 subjects. In 2 it was confined to the legs, while in the third it involved both the arms and legs. A further patient had a solitary episode of erythema nodosum involving the lower limbs. Abdominal bloating and diarrhoea concomitant with the onset of arthralgic symptoms was a constant feature in 5 subjects.

Group II. Prior to reversal of the jejunoileal bypass for the indications illustrated in Table 1, 6/18 subjects $(33 \%)$ suffered episodic arthralgic symptoms similar to those observed in the group I patients. Returning the small intestine to its normal anatomical configuration was associated in all 6 patients with an immediate, complete, and permanent remission of arthropathic symptoms.

Group III. None of the 18 patients in whom weight reduction had been induced by diet or gastroplasty developed symptoms suggestive of the arthropathy observed in the jejunoileal bypass subjects. Minor articular symptoms were present in 8 of these 18 subjects $(44 \%)$ prior to commencing the diet or undergoing gastroplasty. 


\section{Discussion}

This study both confirms previous reports ${ }^{70-13}$ on the development of a characteristic episodic arthropathy following the construction of a jejunoileal bypass and demonstrates its independence from osteomalacia and pre-existing joint disease. The prevalence of this symptom complex, which we have termed jejunoileal arthropathy (JIA) has previously been reported to be between 5 and $20 \% \cdot{ }^{70-12}$ However, these figures are based on patients spontaneously reporting articular symptoms or being referred to specialist rheumatology departments. The incidence of $35 \%$ observed in this study was obtained by direct inquiry as to the presence of musculoskeletal symptoms and signs. While this may have resulted in the inclusion of less severe cases, it is probably a more accurate assessment of the true overall prevalence. Clegg et al. ${ }^{13}$ in the only other study utilising direct questioning, found $52 \%$ of 44 consecutive patients who had undergone jejunoileal bypass to have suffered symptoms suggestive of JIA. The disparity between our findings and those of Clegg et al. ${ }^{13}$ possibly reflects the different type of jejunoileal bypasses performed. In the majority of our subjects $(98 / 107)$ the redundant loop of small bowel was anastomosed to the terminal ileum, ${ }^{5}$ while in the patients studied by Clegg et al. ${ }^{13}$ this loop was connected directly to the colon, ${ }^{17}$ in which position greater bacterial contamination might be expected. ${ }^{10}$ It is of interest that the 9 subjects in our study who had undergone this latter form of small bowel bypass had a higher incidence (5/9) of arthropathic symptoms than that observed in the study as a whole.

Two salient points emerge from our study of those subjects requiring reversal of their intestinal bypasses for the variety of complications illustrated in Table 1. Firstly, the similar incidence of JIA in this group (33\%) to the incidence of JIA in patients in group I $(35 \%)$, who were without other major side effects, implies that articular symptoms do not occur with a greater frequency in the presence of other complications. Secondly, the complete and permanent remission of the arthropathy consequent upon the small intestine being returned to its normal configuration emphasises the total dependence of JIA on the presence of an intestinal bypass and/or a redundant loop of small intestine.

Although the pathogenesis of JIA remains unclear, the total absence of articular symptoms suggestive of JIA in our control group, in whom rapid weight loss was induced without intestinal bypass, would suggest (even though this control group was followed up for a shorter period of time) that metabolic disturbances attributable simply to rapid weight reduction are not in themselves a major factor in inducing JIA.
Immune mechanisms, however, would appear likely to be of prime aetiological significance. Increased levels of complement-containing cryoprecipitates and circulating immune complexes, some of which possess antibodies directed against bacterial antigens, have been reported to occur in patients who develop postoperative joint symptoms. ${ }^{20-22}$ The redundant loop of small intestine would seem to be the probable location for these bacterial antigens, since Elkon et al. ${ }^{23}$ have demonstrated, in 3 patients suffering with JIA, circulating antibodies against organisms isolated from this site. Reversal of the intestinal bypass in all 3 subjects resulted in resolution of their arthropathy and disappearance of these specific antibodies.

In view of the complications associated with jejunoileal bypass it is probable that this operation will be superseded in the treatment of morbid obesity by procedures such as gastroplasty with fewer side effects. ${ }^{1924}$ Work is therefore urgently required to define more clearly the mechanisms underlying both the arthropathy and individual susceptibility to its development and expression. Such investigations, while helping in the management of those suffering with, or liable to develop JIA, could also add to our general understanding of chronic arthritides.

J. P. D. is financially supported by an Arthritis and Rheumatism Council Clinical Research Fellowship.

\section{References}

1 Payne J H, DeWind L T, Commons R R. Metabolic observations in patients with jejuno-colic shunts. Am J Surg 1963; 106: 273-89.

2 The Danish obesity project. Randomised trial of jejuno-ileal bypass versus medical treatment in morbid obesity. Lancet 1979; ï: $1255-8$.

3 Baddeley $R$ M. The results of two techniques of jejuno-ileostomy. Br J Surg 1976; 63: 149.

4 Scott H W, Law D H, Sandstead H H, Lanier V C, Younger R K. Jejuno-ileal shunt in surgical treatment of morbid obesity. Ann Surg 1970; 171: 770-82.

5 Payne J H DeWind L, Schwab C E, Kern W H. Surgical treatment of morbid obesity: sixteen years of experience. Arch Surg 1973; 106: 432-7.

6 Parfitt A M, Miller M J, Frame B, et al. Metabolic bone disease after intestinal bypass for treatment of obesity. Ann Intern Med 1978; 89: 193-9.

7 Backman L, Hallberg D. Some somatic complications after small intestinal bypass operations for obesity. Acta Chir Scand 1975; 141: 790-800.

8 Phillips R B. Small intestinal bypass for the treatment of morbid obesity. Surg Gynecol Obstet 1978; 146: 455-68.

9 Shagrin J W, Frame B, Duncan H. Polyarthritis in obese patients with intestinal bypass. Ann Intern Med 1971; 75: 377-80.

10 Drenick E J, Ament M E, Finegold S M, Corrodi P, Passaro E. Bypass enteropathy; intestinal and systemic manifestations following small-bowel bypass. JAMA 1976; 236: 269-72.

11 Zapanta M, Aldo-Benson M, Biegel A, Madura J. Arthritis associated with jejuno-ileal bypass. Arthritis Rheum 1979; 22: 711-7. 
12 Fenandez-Herlihy L. Arthritis after jejuno-ileostomy for intractable obesity. $J$ Rheumatol 1977; 4: 135-8.

13 Clegg D O, Samuelson C O, Williams H J, Ward J R. Articular complications of jejuno-ileal bypass surgery. $J$ Rheumatol 1980; 7: 65-70.

14 Duncan $H$. Arthropathy and the intestinal bypass operation for obesity. J Rheumatol 1977; 4: 115-7.

15 Iveson J M, Wright V, Duncan $H$, Baddeley $R M$. The musculoskeletal manifestations following small intestinal bypass surgery for gross obesity. Ann Rheum Dis 1979; 38: 495-6.

16 Editorial. Rheumatoid arthritis and the gut. Br Med J 1979; i: 1104.

17 Scott H W, Sandstead H H, Brill A B, Burko H, Younger R K. Experience with a new technique of intestinal bypass in the treatment of morbid obesity. Ann Surg 1971; 174: 560-72.

18 Mason E E, Printen K J, Hartford C E, Boyd W C.
Optimizing results of gastric bypass. Ann Surg 1975; 182: 405-14.

19 Alden J F. Gastric and jejuno-ileal bypass. Arch Surg 1977; 112: 799-806.

20 Wands J R, La Mont J T, Mann E, Isselbacher K J. Arthritis associated with intestinal-bypass procedure for morbid obesity. N Engl J Med 1976; 294; 121-4.

21 Rose E, Espinoza L R, Osterland C K. Intestinal bypass arthritis: Association with circulating immune complexes and HLA-B27. J Rheumatol 1977; 4: 129-34.

22 Ginsberg J, Quismorio F P, DeWind L T, Mongan E S. Musculoskeletal symptoms after jejuno-ileal shunt surgery for intractable obesity. Am J Med 1979; 67: 443-8.

23 Elkon K B, Fagan E, Blankharn I, et al. Bypass arthritis syndrome-clinical and laboratory studies. Ann Rheum Dis 1981; 40: 192-3.

24 Joffe S N. Current status of jejuno-ileal bypass for obesity. Lancet 1981; i: 93. 